\title{
Production of metallurgical-grade silicon from Egyptian quartz
}

\author{
by H.H.M. Ali*, M.H. El-Sadek*, M.B. Morsi*, K.A. El-Barawy*, \\ and R.M. Abou-Shahba ${ }^{\dagger}$
}

\section{Synopsis}

Metallurgical-grade silicon (MG-Si) was successfully produced by carbothermic reduction-smelting of Egyptian quartz using a mixture of carbonaceous materials in a locally made semi-pilot submerged arc furnace. The effects of different technical parameters such as the carbon to silica ratio, smelting time, power input, and weight ratio of carbon sources were investigated. The MG-Si product was characterized by X-ray diffraction (XRD), X-ray fluorescence (XRF), and scanning electron microscopy (SEM). A maximum silicon recovery of about $75 \%$ at a product purity of about $97 \%$ was achieved under the optimum experimental conditions of 80 minutes' smelting time, $48 \mathrm{~kW}$ power input, and a carbon/silica ratio of 0.39 .

Keywords

metallurgical- grade silicon, carbothermic reduction, quartz, charcoal, coke, petroleum coke.

$$
\begin{aligned}
& 2 \mathrm{SiO}_{2(\mathrm{~s}, 1)}+\mathrm{SiC}_{(\mathrm{s})} \rightarrow \\
& 3 \mathrm{SiO}_{(\mathrm{g})}+\mathrm{CO}(\mathrm{g}) \\
& \Delta H_{2000} \mathrm{C}^{\circ}=1364 \mathrm{~kJ} / \mathrm{mol} \\
& \mathrm{SiO}_{2(\mathrm{~s}, 1)}+\mathrm{Si}{ }_{(\mathrm{l})} \rightarrow 2 \mathrm{SiO}(\mathrm{g}) \\
& \Delta H_{2000^{\circ} \mathrm{C}}=599 \mathrm{~kJ} / \mathrm{mol} \\
& \mathrm{SiO}(\mathrm{g})+\mathrm{SiC}_{(\mathrm{s})} \rightarrow 2 \mathrm{Si}{ }_{(1)}+\mathrm{CO}_{(\mathrm{g})} \\
& \Delta H_{2000^{\circ} \mathrm{C}}=167 \mathrm{~kJ} / \mathrm{mol}
\end{aligned}
$$

The slowest of these three reactions are probably the $\mathrm{SiO}_{(\mathrm{g})}$-producing reactions [2] and [3], which consume a major part of the input electrical energy. Silicon can be produced through reaction [4] at temperatures above $1811^{\circ} \mathrm{C}$. The $\mathrm{SiO}$ gas travels upwards in the furnace and is recovered either by reaction with the carbon material (Equation [5]) or by condensation where the temperature is sufficiently low $\left(<1800^{\circ} \mathrm{C}\right)$ (reactions [2 rev.] and [3 rev.]).

$$
\begin{aligned}
& \mathrm{SiO}_{(\mathrm{g})}+2 \mathrm{C}_{(\mathrm{s})} \rightarrow \mathrm{SiC}_{(\mathrm{s})}+\mathrm{CO}_{(\mathrm{g})} \\
& \Delta H_{2000^{\circ} \mathrm{C}}=-78 \mathrm{~kJ} / \mathrm{mol} \\
& 3 \mathrm{SiO}_{(\mathrm{g})}+\mathrm{CO}_{(\mathrm{g})} \rightarrow \\
& 2 \mathrm{SiO}_{2(\mathrm{~s}, \mathrm{l})}+\mathrm{SiC}_{(\mathrm{s})} \\
& \Delta H_{2000^{\circ} \mathrm{C}}=-1380 \mathrm{~kJ} / \mathrm{m} . \mathrm{ol} \\
& 2 \mathrm{SiO}(\mathrm{g}) \rightarrow \mathrm{SiO}_{2(\mathrm{~s}, \mathrm{l})}+\mathrm{Si}_{(\mathrm{l})} \\
& \Delta H_{2000^{\circ} \mathrm{C}}=-606 \mathrm{~kJ} / \mathrm{mol}
\end{aligned}
$$

The condensate-producing reactions [2 rev.) and [3 rev.] are strongly exothermic and are the main factors that contribute to the upwards heat transport in the furnace.

The temperature at the top of the furnace can vary between 1000 and $1700^{\circ} \mathrm{C}$. Typical industrial silicon yields are around $85 \%$ in a

* Central Metallurgical Research and Development Institute (CMRDI), Egypt.

+ Faculty of Science, Al-Azhar University, Egypt.

(C) The Southern African Institute of Mining and Metallurgy, 2018. ISSN 2225-6253. Paper received Jun. 2017; revised paper received Nov. 2017. 


\section{Production of metallurgical-grade silicon from Egyptian quartz}

well -operated furnace. The SiO gas will only be captured by reactions [2 rev.] and [3 rev.]. The temperature has a major effect on the equilibrium conditions for these two reactions Much work has been done in recent years to define the reaction zones inside the silicon furnace (Myrhaug, 2003; Tangstad et al., 2010; Ringdalen and Tangstad, 2012; Asen 2012; Tangstad, 2012; Schei, Tuset, and Tvei, 1998).

In Egypt, tremendous resources of high-quality sands and quartz (the average content of $\mathrm{SiO}_{2}$ is $99 \%$ ) exist in Sinai and in the Eastern Desert. Despite the huge silica resources and the availability of reductants, there is no silicon industry in Egypt. In this paper we investigate the possibility of utilizing the local quartz resource for the production of MG-Si by studying the factors affecting the production process, such as carbon/silica ratio, reduction time, power input, and weight ratio of carbon sources.

\section{Experimental}

\section{Materials}

One ton of quartz from the Al Faleg area, Marsa Alam, Eastern Desert was subjected to a series of crushing cycles using a pilot jaw crusher. The particle size between $16 \mathrm{~mm}$ and $2 \mathrm{~mm}$ was used for the production of MG-Si. XRF analysis showed that quartz consists mainly of $\mathrm{SiO}_{2}$ (99.94\%), with minor amounts of $\mathrm{Fe}_{2} \mathrm{O}_{3}(0.02 \%), \mathrm{Al}_{2} \mathrm{O}_{3}$ $(0.02 \%)$, and $\mathrm{MgO}(0.02 \%)$.Trace amounts of other oxides such as $\mathrm{CaO}(0.002 \%), \mathrm{K}_{2} \mathrm{O}(0.003 \%)$, and $\mathrm{TiO}_{2}(0.0002 \%)$ were detected. XRD analysis was conducted to determine the phase composition of the quartz. Figure 1 shows that all the peak positions match the standard quartz phase.

Different carbon sources such as charcoal, coal, petroleum coke, and wood chips (with a fixed carbon content of 45\%) were used as reductants. Table I shows the approximate chemical analysis of the carbonaceous materials.

\section{Reduction technique}

Reduction-smelting tests were performed in a locally-made electric arc furnace (EAF). The furnace is a submerged single-electrode $(125 \mathrm{~kW})$ furnace powered by five transformers. Smelting tests were conducted in a graphite hearth of $35 \mathrm{~cm}$ diameter which acts as the earth conductor, with a graphite rod $10 \mathrm{~cm}$ in diameter and $120 \mathrm{~cm}$ in length, located in the center of the graphite hearth, acting as the live electrode. The graphite electrode is connected to the terminal of the power transformer through a pure copper tube cooled

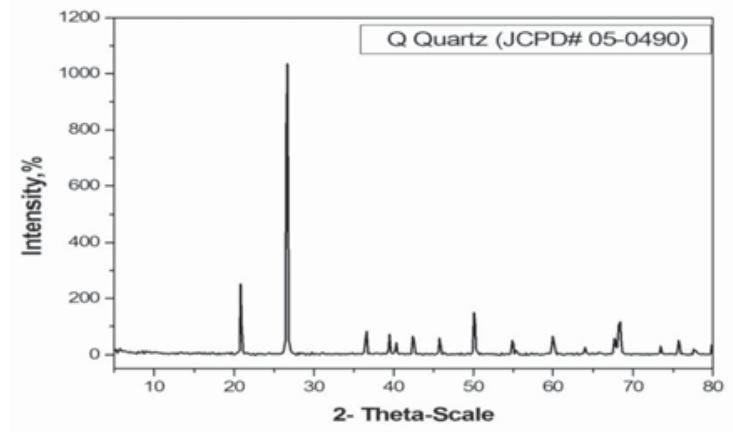

Figure 1-XRD spectrum of the quartz by a flowing current of water. The furnace is tilted on its horizontal axis to pour the molten silicon metal at the end of each experiment. The quartz sample was mixed thoroughly with predetermined amounts of carbonaceous materials according to the following relationship.

The reduction experiments were carried out by introducing about $10 \mathrm{~kg}$ of the mixture through the feeder into the furnace. After smelting, the extent of the reduction process was calculated according to the following formula:

Extent of reduction $\%=\left[\left(\mathrm{Si}_{\mathrm{p}} / \mathrm{Si}_{0}\right] \times 100\right.$ where $\mathrm{Si}_{0}$ is the initial silicon content in quartz and $\mathrm{Si}_{\mathrm{p}}$ is the produced Si metal

\section{Results and discussion}

The data obtained and technical parameters affecting the carbothermic reduction smelting of quartz to produce MGsilicon metal are discussed in the following sections

\section{Charge composition}

\section{Effect of carbon/silica weight ratio}

To ensure a high silicon recovery, it is necessary to maintain the carbon/silica weight ratio of the charge at the required stoichiometric value. A series of experiments was carried out using mixtures of the pure crushed quartz sample with different proportions of coal, petroleum coke, charcoal, and wood chips. Different ratios of fixed carbon to silica $\left(\mathrm{C} / \mathrm{SiO}_{2}\right)$ ranging from 0.30 to 0.45 (i.e. from 1.5 to 2.25 molar ratio of fixed carbon to silicon dioxide) were used in this study. The charges were smelted in the EAF at constant conditions of current (about $0.8 \mathrm{kA}$ ), voltage (about $45 \mathrm{~V}$ ), and power input (about $36 \mathrm{~kW}$ ) for a constant smelting time of 60 minutes. The extent of reduction of silica as a function of the carbon/silica ratio is depicted in Figure 2. It is clear that the reduction extent increases from $15 \%$ to about $30 \%$ as the carbon/silica ratio increases from 0.3 to 0.39 (i.e. from 1.5 to 1.95 molar ratio of fixed carbon to silicon dioxide). The maximum recovery of MG-Si was about $30 \%$. Increasing the $\mathrm{C} / \mathrm{SiO}_{2}$ ratio above 0.39 was accompanied by a decrease in reduction extent. It can be concluded that the optimum $\mathrm{C} / \mathrm{SiO}_{2}$ weight ratio is about 0.39 (1.95 molar ratio of $\left.\mathrm{C} / \mathrm{SiO}_{2}\right)$, which is in good agreement with the published results (Dosaj et al., 1992; Arvidson, Dosaj, and May, 1991).

XRD characterization of the product metal was conducted to ascertain the reasons for these trends. Figure 3 shows the presence of the silicon carbide phase behind silicon metal in the product from a charge containing a $\mathrm{C} / \mathrm{SiO}_{2}$ weight ratio of

Table I

Chemical analysis (\%) of the different types of carbon used as reductants

\begin{tabular}{|l|c|c|c|}
\hline \multirow{2}{*}{} & \multicolumn{3}{|c|}{ Carbon type } \\
\cline { 2 - 4 } & Coal & Pet. coke & Charcoal \\
\hline Moisture & 0.5 & 0.43 & 3.6 \\
Volatile matter & 19.8 & 14.6 & 12.9 \\
Ash & 8.4 & 0.38 & 2.86 \\
Fixed carbon & 71.3 & 84.6 & 80.6 \\
\hline
\end{tabular}




\section{Production of metallurgical-grade silicon from Egyptian quartz}

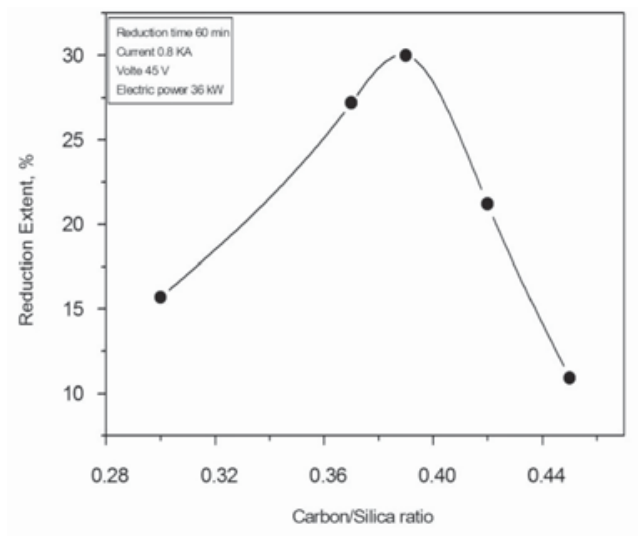

Figure 2-Effect of carbon/silica ratio on the extent of $\mathrm{SiO}_{2}$ reduction

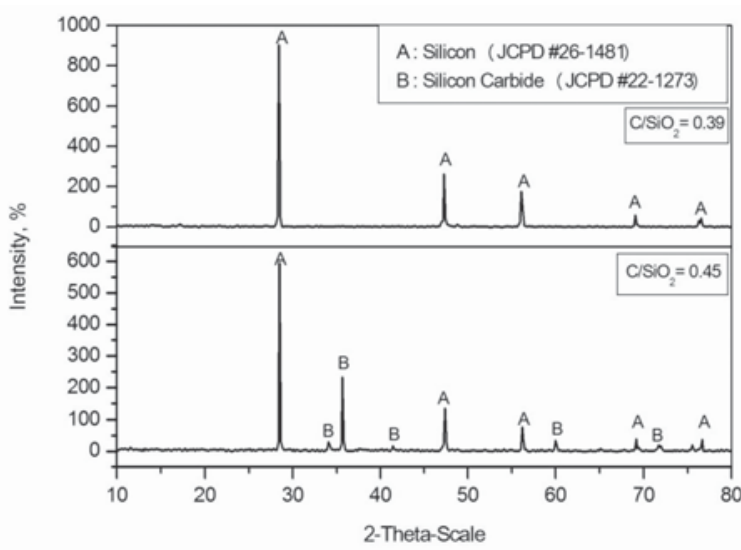

Figure 3-XRD patterns of product from charge containing carbon $/ \mathrm{SiO}_{2}$ ratios of 0.39 and 0.45

0.45 , which indicates that the reaction is not complete. However, with the charge containing a $\mathrm{C} / \mathrm{SiO}_{2}$ weight ratio of 0.39 ( 1.95 molar ratio of $\mathrm{C} / \mathrm{SiO}_{2}$ ), only the silicon metal phase was detected. Smelting with an excess of carbon promoted the formation of an excess of silicon carbide, which lowered the amount of silicon produced. Subsequently, silicon carbide accumulated and filled the hearth of the furnace, which made it necessary to raise the electrode, which increased the temperature in the outer zone of the furnace. This will lead to an increase in the electrode consumption. Therefore, it is important for efficient furnace operation that the furnace is kept in carbon balance (Dosaj $e t$ al., 1992).

\section{Effect of carbon types on MG-Si production at constant carbon/silica weight ratio}

There is no doubt that the carbonaceous reductant in the mix should have a minimum ash content, large reactive surface, low volatile matter content, high electrical resistance, and sufficient mechanical strength for achieving a good silicon yield with acceptable purity. A primary factor affecting the efficiency of the silica reduction process is the reactivity of the carbon reductants. Based on reactivity, purity, and the cost of the reductant, we investigated mixtures of different types of carbonaceous materials (coal, petroleum coke, charcoal, and wood chips). In order to estimate the optimum reductant recipe, we varied the mass of each type of carbonaceous materials while keeping the masses of the other types constant. The mass ratio of fixed carbon to silica was kept constant (0.39) in all the experiments.

\section{Effect of varying charcoal additions}

Charcoal was found to be the best reductant due to its high reactivity, low ash content, and high electrical resistivity, which has a positive influence on the furnace electrical efficiency and process chemistry. A series of experiments was carried out using charges of quartz mixed with constant weights of coal, petroleum coke, and wood chips with different weights of charcoal. The carbon/silica ratio was maintained at 0.39 , and the applied electrical power was about $36 \mathrm{~kW}$ with a smelting time of 60 minutes. Figure 4 shows the variation of the extent of silica reduction as a function of the ratio of charcoal to silica in the charge. The extent of reduction increased with increasing charcoal content in the charge up to $30 \%$ by mass, and then decreased. The initial increase in the extent of reduction is due to the high reactivity of charcoal, which enhances the reduction process and leads to the formation of excess silicon carbide. However, further charcoal additions accelerate the formation of silicon monoxide gas in the outer zone of the furnace, which escapes from the surface of reaction and leads to a decrease in the extent of reduction and lower recovery of silicon metal (Vaish, 2012; Kuhlmann, 1965)

\section{Effect of varying petroleum coke additions}

A series of experiments was performed in which the ratio of petroleum.coke to quartz was varied while keeping the carbon/silica ratio constant at 0.39 . The applied electrical power was about $36 \mathrm{~kW}$ and the smelting time 60 minutes. Figure 5 shows the variation in the extent of reduction as a function of the petroleum coke/quartz ratio.

The extent of reduction increased with increasing petroleum coke additions up to about $28 \%$ by mass, after which further increases in petroleum coke decreased the extent of reduction and the yield of silicon metal. Although petroleum coke plays an important role in the reduction process, it contains ash with a low iron content and much finer material. The introduction of these fines into the

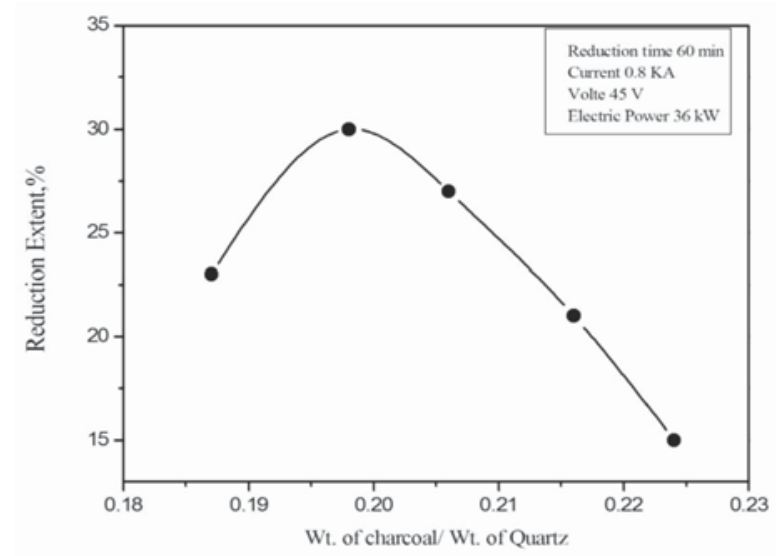

Figure 4-Effect of charcoal to quartz ratio at constant carbon/silica ratio on the extent of reduction 


\section{Production of metallurgical-grade silicon from Egyptian quartz}

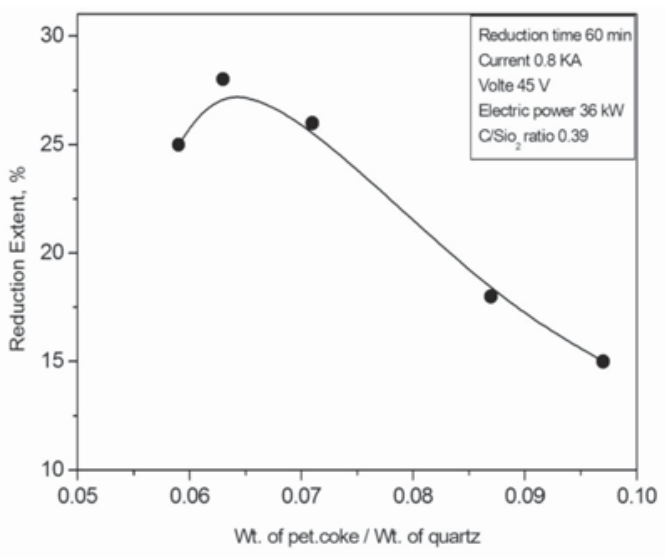

Figure 5-Effect of petroleum coke to quartz ratio at constant carbon/silica ratio on the extent of reduction

furnace results in poor furnace efficiency because it reduces the porosity of the charge, leading to the entrainment and subsequent blowing out of the fines with the furnace off-gas (Kuhlmann, 1965).

\section{Effect of varying coal additions}

Coal has a high electrical resistance and negligible quantities of volatile matter, but contains undesirable impurities such as iron. Figure 6 shows the extent of reduction as a function of the coal/quartz ratio. The extent of reduction increases with increasing coal additions until about $28 \%$ yield, beyond which the yield decreases with further coal additions. This may be due to the coal containing from about 5 to $15 \%$ ash ( $25 \%$ of which is iron oxide). The iron partitions into the silicon metal and affects the purity of the product (Kuhlmann, 1965).

From these results, the optimum charge composition was determined to be $64.63 \mathrm{wt} . \%$ quartz, $4.08 \mathrm{wt} . \%$ coal, 12.6 wt.\% charcoal, 11.77 wt.\% petroleum coke, and $6.92 \mathrm{wt} . \%$ wood chips.

\section{Effect of smelting time}

A series of smelting experiments was conducted on charges containing 64.63 wt.\% quartz, 4.08 wt.\% coal, 12.6 wt.\% charcoal, $11.77 \mathrm{wt} . \%$ petroleum coke, and $6.92 \mathrm{wt} . \%$ wood chips at a $\mathrm{C} / \mathrm{SiO}_{2}$ ratio of 0.39 and power input of $36 \mathrm{~kW}$, while varying the smelting time from 60 to 90 minutes. It was found (Figure 7) that the recovery of silicon metal increased from 28 to $40 \%$ as the smelting time was increased from 60 to 80 minutes. Further increases in smelting time up to 90 minutes decreased the silicon recovery to about $20 \%$. This sharp decrease is due to the evaporation of the silicon metal product in the form of silica fumes as a result of the long smelting time. The optimum smelting time of 80 minutes yielded a silicon recovery of about $40 \%$.

\section{Effect of furnace power input}

The smelting process was investigated at different power inputs ranging from 30 to $60 \mathrm{~kW}$ using charges having a $\mathrm{C} / \mathrm{SiO}_{2}$ ratio of 0.39 and a constant smelting time of 80 minutes. Figure 8 illustrates the variation in silicon recovery with power input. Silicon recovery was increased from about
$20 \%$ to $75 \%$ as the power input was increased from 30 to 48 $\mathrm{kW}$. With further increases in power, silicon recovery decreased, falling to about $30 \%$ at $60 \mathrm{~kW}$ power input.

The optimum recovery of about $75 \%$ of MG-Si was obtained at a power input of $48 \mathrm{~kW}$. This may be due to the power input being sufficient to increase the furnace temperature to a level that enhances the reaction between $\mathrm{SiO}$ gas and SiC to form silicon metal. Higher power inputs, and higher temperatures, lead to the formation of excess SiO gas

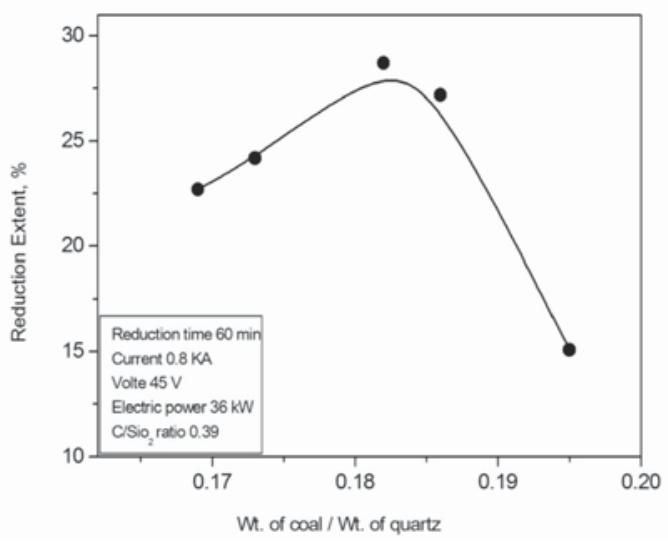

Figure 6-Effect of coal to quartz ratio at constant fixed carbon/silica ratio on the extent of reduction

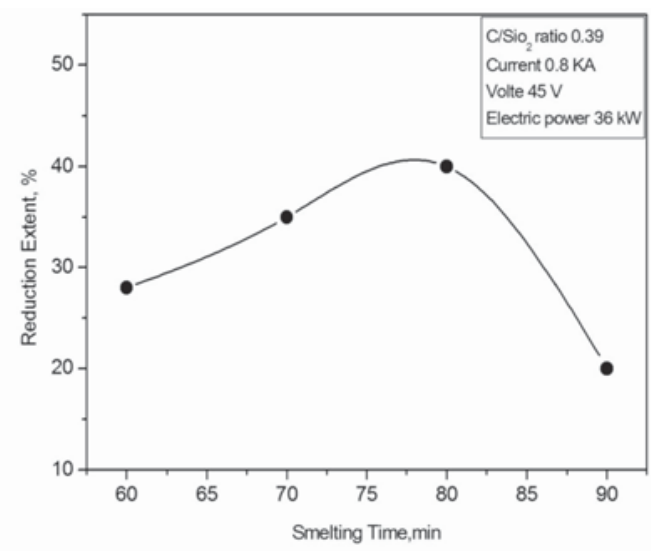

Figure 7-Effect of smelting time on the extent of reduction

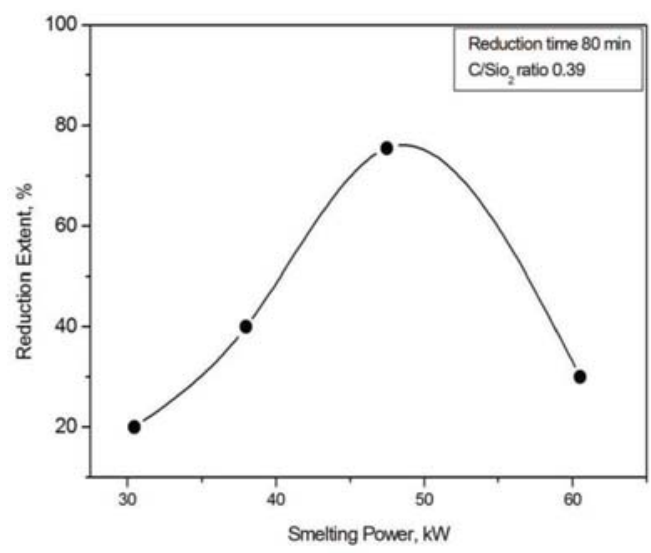

Figure 8-Effect of smelting power on the extent of reduction 


\section{Production of metallurgical-grade silicon from Egyptian quartz}

and consequently increase the silica loss (Mitsuhiro and Hirasawa, 2000)

\section{Evaluation of the MG-silicon product}

Figure 9 displays photographs of the MG-silicon product obtained at the optimum reduction-smelting conditions (carbon/silica mass ratio 0.39 , smelting time 80 minutes, and power input $48 \mathrm{~kW}$ ). The microstructure and chemical composition were investigated using XRD, SEM, and XRF.

\section{$X$-ray diffraction $(X R D)$}

Figure 10 shows the XRD spectrum of the MG-Si produced under optimum conditions, which indicates the presence of silicon metal only.

\section{$X$-ray fluorescence $(X R F)$}

The MG-silicon was chemically analysed by XRF to determine its purity. The results are summarized in Table II. The MGsilicon product contained about $97 \% \mathrm{Si}$ and $1.15 \% \mathrm{Fe}$, with traces of other elements. It is clear that the MG-Si product had low traces of $\mathrm{P}$, and it is noteworthy that no boron was detected. It is known that most impurities such as $\mathrm{Fe}, \mathrm{Al}$, and $\mathrm{Ti}$, contained in the raw materials are transferred to the MGsilicon product.
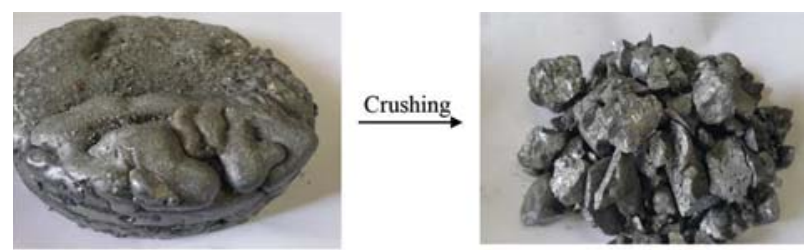

Figure 9-Photographs of MG-Si product

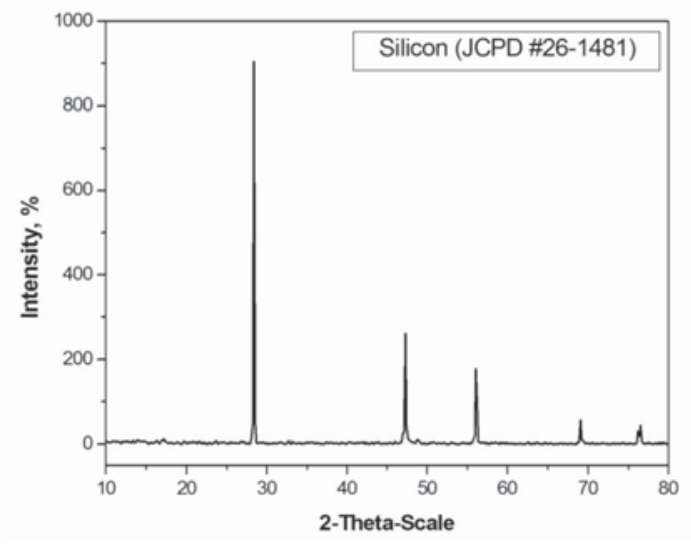

Figure 10-XRD spectrum of MG-silicon produced at optimum conditions

\section{Morphology}

Scanning electron microscopy (SEM) images of the MGsilicon product are shown in Figure 11. A general distribution of silicon metal grains with traces of iron at the grain boundaries is evident.

\section{Conclusions}

MG-Si was produced from Egyptian quartz using a locally made submerged arc furnace, with a recovery of about $75 \%$ and product purity of about $97 \%$ silicon.

The optimum conditions for production of MG-Si are summarized as follows:

> Carbon/silica weight ratio $\left(\mathrm{C} / \mathrm{SiO}_{2}\right) 0.39$

> Charge composition quartz 64.63 wt.\%, coal 4.08 wt.\%, charcoal $12.6 \mathrm{wt} . \%$, petroleum coke $11.77 \mathrm{wt} . \%$, and wood chips $6.92 \mathrm{wt} . \%$

$>$ Smelting time 80 minutes

> Power input $48 \mathrm{kWh}$

> Electrical energy consumption approx. $19 \mathrm{kWh} / \mathrm{kg}$ of silicon metal produced

$>$ Electrode consumption $0.11 \mathrm{~kg} / \mathrm{kg}$ of silicon metal produced

> Silicon metal purity about $97 \%$.

\section{References}

AASLY, K. 2008. Properties and behavior of quartz for the silicon process $\mathrm{PhD}$ dissertation, Norwegian University of Science and Technology, Trondheim.
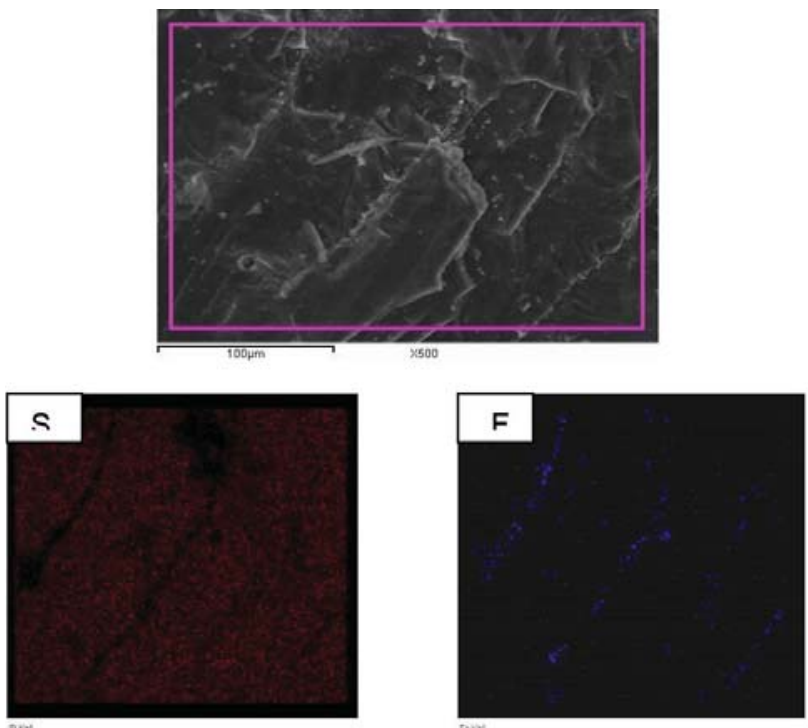

Figure 11-SEM micrographs of the MG-silicon product

Table II

XRF analysis of MG-Si product (wt. \%)

\begin{tabular}{|l|c|c|c|c|c|c|c|c|c|}
\hline Si & Al & Fe & Ca & Na & Ni & P & Mn & Cu & S \\
\hline 96.94 & 0.393 & 1.153 & 1.085 & 0.013 & 0.035 & 0.028 & 0.028 & 0.102 & 0.012 \\
\hline
\end{tabular}




\section{Production of metallurgical-grade silicon from Egyptian quartz}

ARvidson, A.N., DosAJ, V.D., and MAY, J.B. 1991. Silicon smelting process in direct current furnace. US patent 5009703. Dow Corning Corporation.

ASEN, J.V. 2012. Metal-producing mechanisms in the carbothermic silicon process. Master's thesis, NTNU, Norway.

Dosaj, V.D., Haines, C.M., MAY, J.B., and Oleson, J.D. 1992. Control of carbon balance in a silicon smelting furnace. US patent 5174982. Dow Corning Corporation

KuHLmann, A.M. 1965. Silicon metal production. US patent 3215522. )Union Carbide Corp.

Mitsuhiro, T. and HiRASAwa, M. 2000. A two-stage reduction process for silicon production. High Temperature Materials and Processes, vol. 19. pp. 281-297.

MyrhaUG, E.H. 2003. Non-fossil reduction materials in the silicon process properties and behavior. PhD thesis, Norwegian University of Science and Technology, Trondheim.

PV Education. 2013. Refining silicon. http://pvcdrom.pveducation.org/ MANUFACT/REFINE.HTM

RingDAlEn, E. and TANGSTAD, M. 2012. Reaction mechanisms in carbothermic production of silicon, study of selected reactions. Proceedings of the TMS International Smelting Technology Symposium: Incorporating the 6th Advances in Sulfide Smelting Symposium. Downey, J.P., Battle, T.P., and White, J.F. (eds.).

http://onlinelibrary.wiley.com/doi/10.1002/9781118364765.ch24/pdf

Schei, A., Tuset, J.K., and Tvei, H. 1998. Production of high silicon alloys. Tapir Forlag, Trondheim, Norway.

TAngstad, M., KsiazeK, M., Andersen, V., and Ringdalen, E. 2010. Small scale laboratory experiments simulating an industrial silicon furnace. Infacon 12. Proceedings of the Twelfth International Ferroalloys Congress: 'Sustainable Future', Helsinki, Finland, 6-9 June 2010. Vartiainen, A. (ed.). Outotec Oyj, Oslo. pp.661-669.

TANGSTAD, M. 2012. Staged heat and mass balance of the Si process. Unpublished report, SINTEF, Trondheim, Norway.

VAISH, A.K. 2012. Production of ferro-silicon and calcium silicon alloys. National Metallurgical Laboratory, Jamshedpur, India. http:// http://eprints.nmlindia.org/5785/1/6.01-6.17.PDF 